DOI: 10.1002/adom.((please insert DOI)

\title{
Amplified Spontaneous Emission in Pentathienoacene Dioxides by Direct Optical Pump and by Energy Transfer: Correlation with Photophysical Parameters
}

Juan Casado ${ }^{* 1}$, Víctor Hernández ${ }^{1}$, Juan T. López Navarrete ${ }^{* 1}$, Manuel Algarra ${ }^{2}$, Demetrio A. da Silva Filho ${ }^{3}$, Shigehiro Yamaguchi ${ }^{4}$, Raquel Rondão, ${ }^{5}$ J. Sergio Seixas de Melo, ${ }^{5}$ Victor Navarro-Fuster ${ }^{6}$, Pedro G. Boj, ${ }^{7}$ María A. Díaz-García*6

${ }^{1}$ Department of Physical Chemistry, University of Málaga, Campus de Teatinos s/n, Málaga 29071, Spain

${ }^{2}$ Centro de Geología, Departamento de Geociencias, Ambiente e Ordenamento do Território do Porto, Faculty of Science, University of Porto, Rua do Campo Alegre, 687, 4169-007 Porto, Portugal.

${ }^{3}$ Institute of Physics, University of Brasilia, 04455, DF, 70919-970, Brazil

${ }^{4}$ Department of Chemistry, Graduate School of Science, Nagoya University, Chikusa, Nagoya, Japan ${ }^{5}$ Department of Chemistry, University of Coimbra, P3004-535 Coimbra, Portugal

${ }^{6}$ Dpto. Física Aplicada and Instituto Universitario de Materiales de Alicante, Alicante 03080, Spain ${ }^{7}$ Dpto. Óptica and Instituto Universitario de Materiales de Alicante, Alicante 03080, Spain

*To whom correspondence should be addressed. E-mail: (J.C.) casado@uma.es, (M.A.D-G) maria.diaz@ua.es

Keywords: oligothienoacenes, dioxide oligothienoacenes, photophysics, quantum chemical calculations, energy transfer, laser properties. 
Abstract. We report the observation of amplified spontaneous emission (ASE), under optical pump, in polystyrene films doped with two pentathienoacene derivatives functionalised with thienyl-S,S-dioxide groups (compounds $\mathbf{2}$ and 3). The effect of the dioxide groups on the ASE properties has been analysed by comparing the performance with that of its corresponding non-oxidized analogue (1). Films containing either 2 or 3 showed ASE at 511 and $574 \mathrm{~nm}$ respectively, when excited directly (at $435 \mathrm{~nm}$ ) on their absorption bands, showing thresholds and linewidths larger than those obtained from films doped with 1, pumped at $355 \mathrm{~nm}$. ASE was also observed under excitation at $355 \mathrm{~nm}$, in samples containing $\mathbf{1}$ (host) and either $\mathbf{2}$ or $\mathbf{3}$ (guests), due to energy transfer from host to guest. For the blends with $\mathbf{3}$, ASE threshold is lower than that obtained when the films are excited directly. Results have been interpreted in terms of photophysical parameters such as absorption capacity, fluorescence efficiency, singlet-to-triplet intersystem crossing leading to triplet-triplet re-absorptions, bimolecular energy transfer efficiency, efficiency of internal conversion process, etc. State-of-the-art quantum chemical calculations were further used in the interpretation of the experimental results. 


\section{Introduction}

Submitted to

Oligothiophenes are among the most extensively studied families of conjugated oligomers in organic electronics. ${ }^{1-4}$ They have shown potential for various types of applications, such as field-effect transistors (FETs), light emitting diodes (LEDs), solar cells and optically-pumped lasers. Oligothienoacenes constitute relatively novel oligothiophenes, developed following the prospects of oligoacenes, in which the thiophene rings are fused. These materials are of interest to various applications since they combine the rigid planarity of acenes with the chemical stability of oligothiophenes. The planarization of the molecular backbone facilitates intermolecular overlap, which is an important requirement for efficient charge transport. In fact, field-effect transistors based on these materials have been demonstrated..$^{5-14}$

Among the various optoelectronic applications for which oligothiophenes and oligothienoacenes have been developed, one of interest for this work is the organic solid-state laser. $^{15-18}$ The use of organic materials in this application is motivated by a unique property related with their broad photoluminescence (PL) spectra which serves to tune the laser wavelength over a wide range. Soluble organic materials have an additional advantage of easy processability, which allows the deposition in the form of thin films by inexpensive techniques, such as spin coating, photolithography or ink-jet printing.

In order to have good laser materials their properties, at both molecular and macroscopic level (type of arrangement in the solid state), need to be understood and optimized. Firstly, at a molecular level, the desirable properties ${ }^{19}$ are: (i) to have strong ground state singlet absorption (high molar extinction coefficient values), (ii) high photoluminescence (PL) quantum yield, (iii) photochemical stability under intense excitation, (iv) a region of strong luminescence well out of the absorption region, (v) low quantum yield 
Submitted to

of intersystem crossing to triplet states (and also of singlet oxygen sensitization) and (vi) minimal overlap between the singlet absorption and the absorption regions from both, triplet states and singlet excited states. All these parameters depend on the molecular structure and can be modified by chemical design. The macroscopic organization is, however, more difficult to control..$^{20,21,22}$

From a practical point of view, one of the simplest methods to identify the presence of stimulated emission in a certain material consists in the observation of amplified spontaneous emission (ASE) when the material is prepared as a waveguide film. ${ }^{15-18,23}$ The presence of ASE is evidenced by the observation of a collapse of the width of the PL spectrum at a certain pump intensity, when the film is optically pumped with a pulsed optical source. Spectral narrowing is normally accompanied by a large enhancement of the output intensity and accounts for the presence of gain due to stimulated emission. The pump intensity at which spectral narrowing due to ASE is observed is called the ASE threshold. This has been the parameter most commonly used in the literature to evaluate the potential of a given material for lasing applications. Low ASE thresholds are required for high performance. ${ }^{15-18}$

The laser properties of a larger variety of organic materials, including small molecules, oligomers, polymers and dendrimers, have been investigated. ${ }^{15-18}$ With regards to small molecules and oligomers, they are generally studied when dissolved into inert polymers which are then deposited, by spin- coating, as thin films. This allows improving the mechanical properties of the films, reducing waveguide propagation losses, as well as preventing molecular aggregation, which often leads to PL quenching. Generally, films are opticallypumped at a wavelength close to the maximum absorption of the active molecule. A strategy aiming to reduce self absorption, and therefore the threshold, has consisted in separating absorption and emission by using the concept of energy transfer by dipole-dipole coupling 
(i.e. Förster energy transfer). ${ }^{15-18,24-26}$ This can be done by using a fluorescent matrix whose PL spectrum overlaps with the absorption of the molecule providing ASE. Another possibility is to use an inert polymer matrix containing two compounds: one (the host), which absorbs the excitation light, and another one (the guest) that receives it.

The laser properties of various types of oligothiophenes have been previously studied. ${ }^{27-30}$ Most reports focused on dioxide or sulfoxide derivatives, i.e., oligothiophenes in which the central thiophene ring has its sulfur atom selectively oxidized to its dioxide form, or thiophene S,S-dioxides. At the early stages of those investigations, dioxide derivatives were developed with the aim of obtaining new n-type semiconductors (oligothiophenes are mostly p-type). However, since they showed high solid-state PL efficiencies while maintaining good chemical stability, subsequent studies focussed in their emission properties, in view of their potential for LEDs. ${ }^{31-33}$ The large solid-state PL efficiencies measured for these systems were due to the reduction of nonradiative processes in the dioxide molecules induced by the variation of both, the solid state supramolecular organization which minimizes PL quenching and the single molecule properties. ${ }^{34,35}$

Concerning oligothienoacenes, there is little information with regards to their laser properties. ASE in oligothienoacene-based thin films was reported for the first time by some of us. $^{36}$ In particular, ASE was observed in polystyrene (PS) films containing the pentathienoacene derivative 2,6-Bis-triisopropylsilanyl- $\alpha$-pentathienoacene (BT-PTA or compound 1, Figure 1). The most interesting result was that ring fusion -comparison made with the oligothiophene counterparts- lead to a significant decrease (one order of magnitude) in the ASE threshold. 

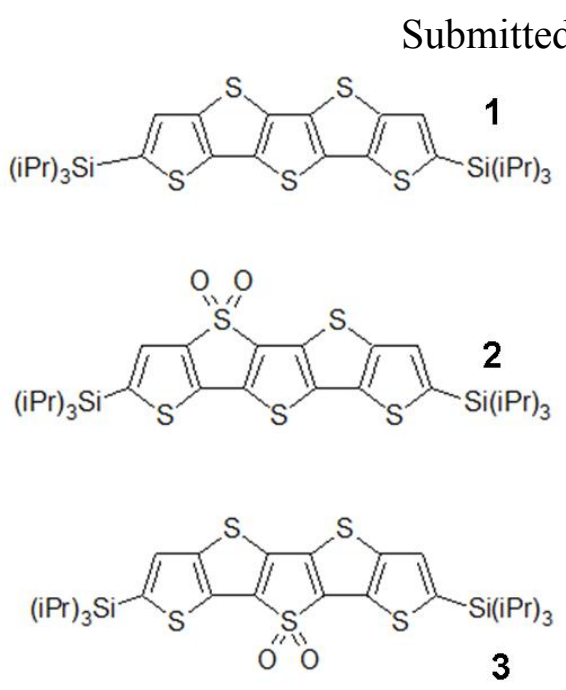

Figure 1. Chemical structure of the three pentathienoacene derivatives studied here: $\mathbf{1}$ (non-oxidized); 2 and $\mathbf{3}$ (substituted with thienyl-S,S-dioxide groups in different positions).

The knowledge that functionalization of oligothiophenes with thienyl-S,S-dioxide groups had lead to improved solid state photoluminescence and stimulated emission, prompted us to investigate the ASE properties of oxidized oligothienoacenes. The first synthesis of pentathienoacene dioxides has been published by Suzuki et al. ${ }^{37}$ aiming at improving semiconductor performance such as already done with oligothiophenes. ${ }^{27-33}$ Accordingly to this, we were prompted to investigate the effect of the functionalization of oligothienoacenes with thienyl-S,S-dioxide groups on the ASE properties, or oxidized pentathienoacenes $\mathbf{2}$ and $\mathbf{3}$ (see Fig. 1). Results have been compared to those already reported for films containing the non-oxidized derivative $1 .^{36}$ To guide the interpretation of the ASE data, a comprehensive investigation of their photophysical properties in solution was here performed. This study includes: (i) Absorption and fluorescence measurements at room and low temperature to determine singlet extinction coefficients, fluorescence quantum yields, lifetimes and rate constants; (ii) Quantum chemical calculations of the electronic structure of the molecules of interest together with an evaluation of the vibronically resolved linear absorption and fluorescence spectra; and (iii) transient absorption (with laser flash photolysis) experiments to obtain the photophysical parameters for the triplet states. A second goal of the 
Submitted to

work was to investigate the possibility of obtaining ASE through energy transfer from compound $\mathbf{1}$ (used as host) to either $\mathbf{2}$ or $\mathbf{3}$ (used as guests), in films containing two derivatives $(\mathbf{1}+\mathbf{2}$ or $\mathbf{1}+\mathbf{3})$. Prior to this study, a detailed investigation of the energy transfer process (Stern-Volmer plots) between $\mathbf{1}$ and $\mathbf{2}$ and between $\mathbf{1}$ and $\mathbf{3}$ was conducted in solution.

\section{Experimental}

Optical absorption and fluorescence in solution. Compounds 1-3 were synthesized as reported elsewhere. ${ }^{12,37}$ All solvents were of spectroscopic or equivalent grade and used without further treatment, except for ethanol, that was dried and purified by distillation over $\mathrm{CaO}$. Absorption and fluorescence spectra (in THF and/or ethanol) were recorded on a Shimadzu UV-2100 spectrometer and on a Horiba-Jobin-Ivon SPEX Fluorog 3-2.2. apparatus, respectively. All the fluorescence spectra were corrected for the wavelength response of the system. The fluorescence quantum yields $\left(\phi_{\mathrm{F}}\right)$ were measured using as standards quaterthiophene $\left(\phi_{\mathrm{F}}=0.18\right.$ in dioxane $)$ and quinquethiophene $\left(\phi_{\mathrm{F}}=0.36 \text { in dioxane }\right)^{38}$ or perylene in acetonitrile $\left(\phi_{\mathrm{F}}=0.87\right)^{52}$. Low temperature measurements were carried out in solutions of the sample in MeTHF. An OptistatDN Cryostat was used. Fluorescence decays were measured using a home-built ps time correlated single photon counting (TCSPC) apparatus described elsewhere. ${ }^{39}$ Fluorescence decays and the instrumental response function (IRF) where collected using 4096 channels in a $0.814 \mathrm{ps} /$ channel scale, until $5 \times 10^{3}$ counts at the maximum were reached. The full width at half maximum (FWHM) of the IRF was about 22 ps and was highly reproducible with identical system parameters. Deconvolution of the fluorescence decay curves was performed using the modulating functions of Striker. ${ }^{40}$

Theoretical calculations. Quantum-chemical calculations using time-dependent density functional theory (TDDFT) were performed in the gas-phase to obtain the equilibrium 
Submitted to

structures and the electronic properties of the ground $\left(\mathrm{S}_{0}\right)$ and first excited state $\left(\mathrm{S}_{1}\right)$ of the molecules of interest. For all calculations reported here, the isopropyl groups have been replaced by methyl groups to reduce the computational cost. The B3LYP exchangecorrelational functional $^{41,42}$ and the $6-31 \mathrm{G}(\mathrm{d}, \mathrm{p})^{43-45}$ basis set was used in all calculations, as implemented in the Gaussian'09 package. An algorithm included in this version of Gaussian' $09^{46}$ was used to generate a vibronically resolved absorption spectrum and emission to allow for a direct comparison with the experimental data. ${ }^{47,48}$

Laser Flash-Photolysis and transient absorption spectra. Transient triplet-triplet absorption spectra were obtained with an Applied Photophysics LKS60 laser flash photolysis apparatus pumped by a Nd:YAG laser (Spectra Physics) and using a Tektronix TDS 3052B digital analyzer. $^{49,50}$ First-order kinetics were observed for the decay of the lowest triplet state. Special care was taken in determining triplet yields, namely to have optically matched dilute solutions (absorbance $\approx 0.2$ in a $10 \mathrm{~mm}$ square cell) and low laser energy $(\leq 2 \mathrm{~mJ})$ to avoid multiphoton and T-T annihilation effects. Triplet molar absorption coefficients were obtained by the energy transfer method ${ }^{51}$ and were determined using naphthalene $\left(\varepsilon_{\mathrm{T}}=24500 \mathrm{M}^{-1} \mathrm{~cm}^{-}\right.$ $\left.{ }^{1}\right)^{52}$, as triplet energy donor. The concentrations for the compounds studied were $10^{-5} \mathrm{M}$ and they were dissolved in a solution of naphthalene $(20 \mathrm{mM})$ in THF or ethanol. Further details on the experimental procedures and equations used can be found in ref. 13 and in Supplementary Material. ${ }^{50}$

Thin film preparation and optical characterization. Films consisting of PS (Sigma Aldrich, $\mathrm{M}_{\mathrm{w}}=35000 \mathrm{~g} / \mathrm{mol}$ ), used as inert polymer, doped with one or two of the oligothienoacenes 13, were deposited by the spin-coating technique over glass substrates from dichloromethane solutions. In particular, films containing only one of the derivatives ( 2 or $\mathbf{3})$ were prepared in order to investigate the presence of ASE when pumping directly into their absorption bands. 
A concentration of $10 \mathrm{wt} \%$ with respect to PS was used, since in our previous work we determined that it provided the best performance in the case of films doped with $\mathbf{1}$. For the experiments aiming to achieve energy transfer from $\mathbf{1}$ (host, donor) to either $\mathbf{2}$ or $\mathbf{3}$ (guest, acceptor), we deposited films containing 10 wt. \% of $\mathbf{1}$ and a varying amount (between 3 and 15 wt. \%) of 2 or 3. Film thickness (between 500 and $800 \mathrm{~nm}$ ) was measured by means of an interferometer coupled to an optical microscope.

The absorption spectra of the films were measured using a Jasco V-650 spectrophotometer. The absorption coefficient for a film of thickness $h$, at a given wavelength $\lambda$ was calculated according to $\alpha_{\lambda}=2.3 A_{\lambda} / h$, where $A_{\lambda}$ is the absorbance or optical density. PL spectra were obtained in a Jasco FP-6500 fluorimeter, exciting the samples at 355, 419 and $428 \mathrm{~nm}$ with an angle of $60^{\circ}$ respect to the normal to the film, for compounds 1,2 and 3 respectively, and then collecting the emitted beam in reflection at a $30^{\circ}$ angle, in order to avoid the pump beam.

In order to investigate the capability of these films to show stimulated emission, we used a typical experimental setup to identify the presence of ASE. Excitation was performed in a perpendicular direction with respect to the film with a stripe of light of $(0.53 \times 3.50) \mathrm{mm}^{2}$, achieved with a cylindrical lens and an adjustable slit. The energy of the pulses was controlled using calibrated neutral density filters. The laser beam was expanded, collimated and only the central part was selected, in order to ensure uniform intensity. The pump stripe was placed right up to the edge of the film where the emitted light was collected with an Ocean Optics USB2000-UV-VIS fiber spectrometer. Samples for energy transfer experiments, doped with compound $\mathbf{1}$ and either $\mathbf{2}$ or $\mathbf{3}$, were photopumped with a pulsed Nd:YAG laser (10 Hz, $10 \mathrm{~ns})$ operating at $355 \mathrm{~nm}$, that is close to the maximum absorbance of the host (1). On the other hand, films doped with only one derivative ( 2 or 3 ), were excited with the first anti-Stokes 
line (435 nm) of a $\mathrm{H}_{2}$ Raman cell, pumped with the frequency doubled $532 \mathrm{~nm}$ line of the Nd:YAG laser.

\section{Results and discussion}

3.1. UV-vis absorption and photoluminescence in solution. Figure 2 displays the absorption and emission spectra of $\mathbf{2}$ and $\mathbf{3}$ in THF solution, both at room (293K) and low temperature $(80 \mathrm{~K})$.
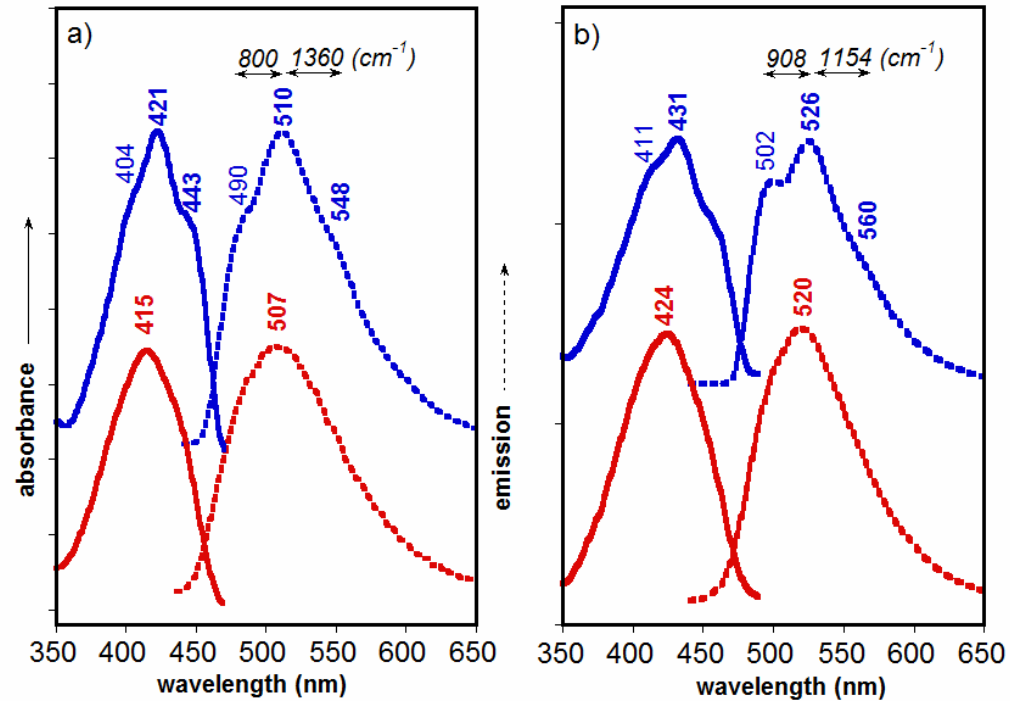

Figure 2. UV-Vis absorption (full lines) and fluorescence (dashed lines) spectra in THF of 2 (a) and 3 (b) at room $(293 \mathrm{~K})$ and low $(80 \mathrm{~K})$ temperature (bottom red and top blue lines respectively).
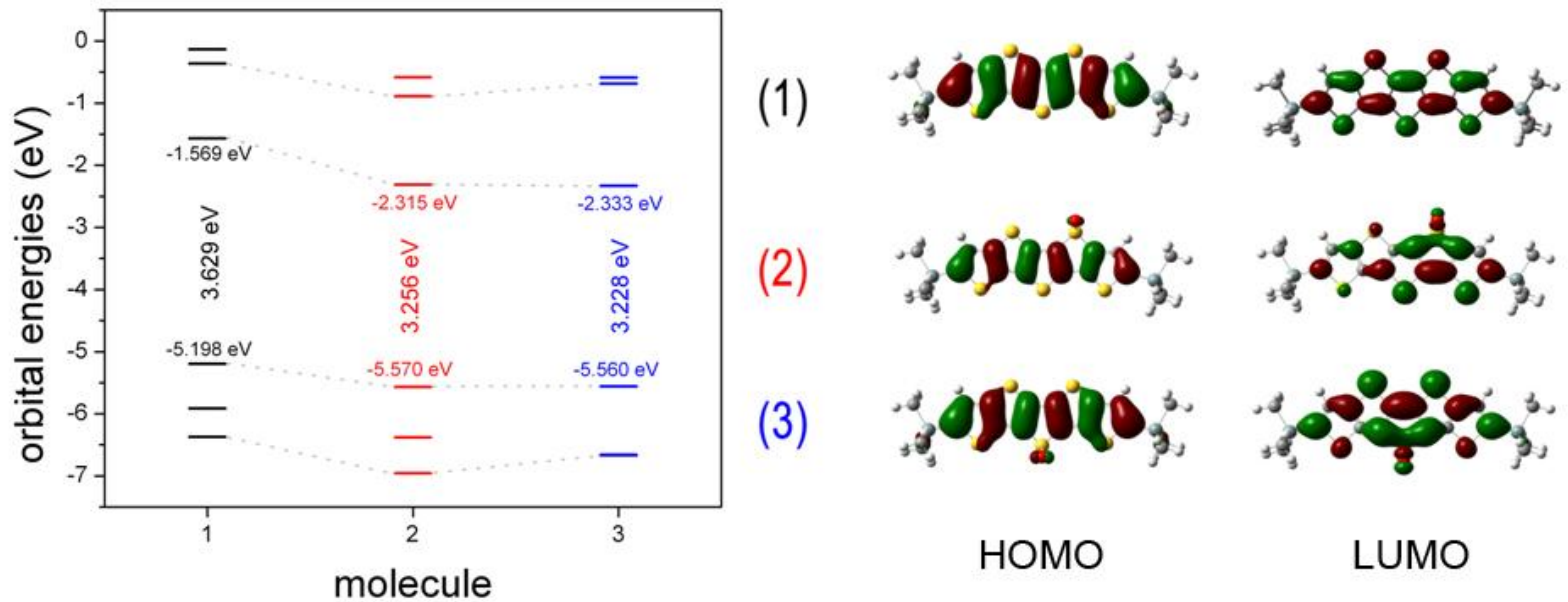

HOMO

LUMO

Figure 3. DFT/B3LYP/6-31G** orbital energies and HOMO-LUMO differences for molecules 1, 2 , and 3. 
At room temperature (RT), broad and structureless spectra were obtained. Spectra for $\mathbf{3}$ are red-shifted by around $10 \mathrm{~nm}$ with respect to those of $\mathbf{2}$. Taking into account that the lowlying absorption bands in these compounds are due to one-electron HOMO-LUMO excitations, the energies of these frontier orbitals can account for the behaviour of the absorption bands. Indeed, the B3LYP calculations in Figure 3 show that the sulfonation at the center of the molecule has a greater influence in the stabilization of the LUMO orbital (lesser in the HOMO) resulting in a narrower HOMO-LUMO and optical gaps. Comparison of spectra for compounds $\mathbf{2}$ and $\mathbf{3}$ (Figure 2) to those of $\mathbf{1},{ }^{12,37}$ shows that sulfonation clearly redshifts the absorption and emission bands. This effect can be ascribed to a larger stabilization of the LUMO energy in $\mathbf{2}$ and $\mathbf{3}$ regarding 1, compared to a smaller HOMO stabilization (Figure 3 left). This is due to the electron acceptor character of the $\mathrm{SO}_{2}$ group and to the plausible increment of electron delocalization upon removing the lone electron pair of the sulfur on the thiophene aromaticity increasing the delocalizability of the remaining $\mathrm{p}_{z}$ electrons and whole conjugation. In Figure 3 (right) the topologies of the HOMO and LUMO orbitals are shown. It is observed that the HOMO wavefunctions for the three molecules are similar, in agreement with their uniform HOMO energies. In contrast, the LUMOs of $\mathbf{2}$ and $\mathbf{3}$ suppose a drift of the electron density towards the $\mathrm{SO}_{2}$ groups, which justifies that the HOMO-LUMO excitation gains a certain character of electron density transference from the carbon-carbon double-bonds to the oxygens or from the non-oxidized rings to the dioxide ring. The existence of this type of CT interaction, both in the absorption as in the emission, might explain that the spectra of $\mathbf{2}$ and $\mathbf{3}$ are devoid of vibrational resolution in comparison with that of 1 .

The absorption and emission spectra at low temperature $(80 \mathrm{~K})$ were obtained in order to get insights on the vibrational progressions and electron-vibration coupling which can influence the energy transfer processes. ${ }^{53}$ Compared to those at RT, the low temperature 
Submitted to

spectra evidence the existence of three vibronic peaks both in the absorption and in the emission spectra of $\mathbf{2}$ and $\mathbf{3}$. The spectra for the non-oxidized compound $\mathbf{1}$ were previously published. ${ }^{12}$ At RT the absorption spectrum of $\mathbf{1}$ showed a partially resolved vibrational progression, which is not common to observe with unsubstituted or substituted $\alpha$-linked oligothiophenes, and that becomes a singular property of acenes and heteroacenes due to their rigidified planar structure. The PL spectrum of $\mathbf{1}$, also structured, was slightly shifted with respect to the absorption, indicating that geometric changes upon electronic excitation were small, thus indicating that the coupling of vibrational modes and the electronic excitation was similar in both ground and excited states. ${ }^{22}$

It is important to discuss the effect of sulfonation on the photophysical properties, such as absorption strength $\left(\varepsilon_{\mathrm{s}}\right)$ fluorescence quantum efficiency $\left(\phi_{\mathrm{F}}\right)$, fluorescence lifetime $\left(\tau_{\mathrm{F}}\right)$ and radiative and non-radiative rate constants, defined as $\mathrm{k}_{\mathrm{F}}=\phi_{\mathrm{F}} / \tau_{\mathrm{F}}$ and $\mathrm{k}_{\mathrm{NR}}=\left(1-\phi_{\mathrm{F}}\right) / \tau_{\mathrm{F}}$ respectively. Some of these parameters have been reported elsewhere, ${ }^{37}$ but they have been measured again in this work in order to have a uniform set of data (overall set of photophysical parameters and rate constants), obtained under the same conditions (solvent, temperature, etc.). Results are displayed in Table 1.

Table 1- Spectroscopic (wavelength absorption, $\lambda_{a b s}^{\max }$ in $\mathrm{nm}$, and fluorescence maxima, $\lambda_{\text {fluo }}^{\max }$ in $\mathrm{nm}$, together with molar extinction coefficient, $\varepsilon_{S}$ ) and photophysical parameters (fluorescence quantum yield, $\phi_{F}$, lifetime, $\tau_{F}$ and radiative $k_{F}$ and radiationless $k_{N R}$ rate constants) for compounds 1-3 in THF and ethanol at room temperature (293 K). $\Delta_{\mathrm{SS}}$ is the Stokes shift.

\begin{tabular}{|c|c|c|c|c|c|c|c|c|}
\hline & $\lambda_{a b s}^{\max }$ & $\lambda_{\text {fluo }}^{\max }$ & $\varepsilon_{\mathrm{S}} / \mathrm{M}^{-1} \mathrm{~cm}^{-1}$ & $\phi_{\mathrm{F}}$ & $\tau_{\mathrm{F}} / \mathrm{ns}$ & $\mathrm{k}_{\mathrm{F}} / \mathrm{ns}^{-1}$ & $\mathrm{k}_{\mathrm{NR}} / \mathrm{ns}^{-1}$ & $\Delta_{\mathrm{ss}} / \mathrm{nm}$ \\
\hline 1 (THF) & 355 & 405 & $36300(a)$ & $0.24(\mathrm{~b})$ & $\begin{array}{c}0.10^{*} \\
0.40^{* *}\end{array}$ & $\begin{array}{c}2.4^{*} \\
0.6^{* *}\end{array}$ & $\begin{array}{c}7.6^{*} \\
1.9^{* *}\end{array}$ & 50 \\
\hline $1(\mathrm{EtOH})$ & 352 & 402 & & $0.16(b)$ & $\begin{array}{c}0.2^{*} \\
0.4^{* *}\end{array}$ & $\begin{array}{c}0.8^{*} \\
0.4^{* *}\end{array}$ & $\begin{array}{l}4.20 \\
2.10\end{array}$ & 50 \\
\hline 2 (THF) & 415 & 510 & 23800 (a) & $0.76(\mathrm{~d})$ & $5.3(\mathrm{a})$ & 0.143 & 0.0453 & 95 \\
\hline \multicolumn{9}{|l|}{$2(\mathrm{EtOH})$} \\
\hline 3 (THF) & 422 & 525 & 20400(a) & 0.82 (b) & 6.52 & 0.126 & 0.0276 & 103 \\
\hline $3(\mathrm{EtOH})$ & 423 & 540 & & $0.81(b)$ & 8.02 & 0.101 & 0.0237 & 117 \\
\hline
\end{tabular}

*major component of a biexponential decay.

** major component at $410 \mathrm{~nm}$ of a biexponential decay.

(a) Values determined previously in ref. 13. 
(b) Reference used: $\alpha 4$ in dioxane $\left(\phi_{\mathrm{F}}=0.18\right)$; see experimental section for further details.

(c) Reference used: $\alpha 5$ in dioxane $\left(\phi_{F}=0.36\right)$ ); see experimental section for further details.

(d) Reference used: Perylene in acetonitrile $\left(\phi_{F}=0.87\right)$; see experimental section for further details.

From a careful observation of data in Table 1 it is worth emphasizing the following behaviours that will be detailed in next sections: i) The absorption strength decreases upon sulfonation from $36300 \mathrm{M}^{-1} \mathrm{~cm}^{-1}$ in $\mathbf{1}$ to 23800 and $20400 \mathrm{M}^{-1} \mathrm{~cm}^{-1}$, in $\mathbf{2}$ and 3 respectively; ii) The fluorescence quantum yield experiences a three-fold increase from $\mathbf{1}\left(\phi_{\mathrm{F}}=0.24\right)$ to $\mathbf{2} / \mathbf{3}$ $\left(\phi_{\mathrm{F}}=0.76\right.$ and 0.82 respectively) which might be ascribed to the reduction of the efficacy of the non-radiative processes as accounted by the decrease of the non-radiative rate constants $\left(k_{\mathrm{NR}}=7.6 \mathrm{~ns}^{-1}\right.$ for 1 and $k_{\mathrm{NR}}=0.0453 / 0.0276 \mathrm{~ns}^{-1}$ in 2/3); and iii) Fluorescence lifetimes increase upon sulfonation from $0.10 \mathrm{~ns}$ for $\mathbf{1}$ to $5.3 \mathrm{~ns}$ and $6.52 \mathrm{~ns}$ for $\mathbf{2}$ and $\mathbf{3}$ respectively. ${ }^{37}$

3.2. Quantum chemical calculations. Figure 4 displays DFT//B3LYP/6-31G** theoretical absorption and fluorescence spectra of $\mathbf{2}$ and $\mathbf{3}$ that include the vibronic progression for the $\mathrm{S}_{0} \rightarrow \mathrm{S}_{1}$ and $\mathrm{S}_{1} \rightarrow \mathrm{S}_{0}$ transitions.
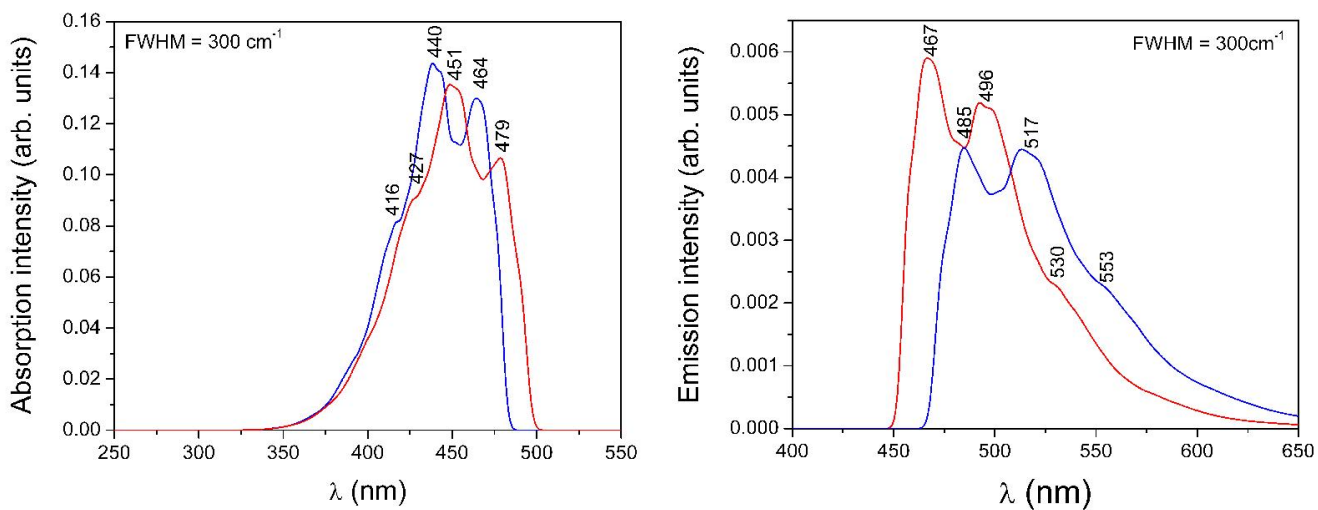

Figure 4. Vibronically resolved absorption (left) and emission (right) of 2 (red) and 3 (blue) together with an indication of the wavelength for each of the the main features. Each theoretical transition (stick transition) was represented by a Gaussian with FWHM equal to $300 \mathrm{~cm}^{-1}$. 
The theoretical absorption spectra of compounds $\mathbf{2}$ and $\mathbf{3}$ reproduce quite well those observed experimentally. A one-to-one comparison can be made between the various vibronic components observed in the experimental and on the theoretical spectra. Three main vibronic components (i.e., 0-0, 0-1, 0-2) are observed (see Figure 4a) at around 464, 440, 416 (sh) for compound 2 and at around 479, 451, 427(sh) for compound 3. Similar progressions were observed in the experimental spectra shown in Figure 2. The more intense component in both the experiment and the calculation is the $0-1$ transition. The theoretical emission spectra also show the existence of various vibronic main components (i.e., 0-0, 0-1, and 0-2) at around $467,496, \mathrm{~A}$

and $530 \mathrm{~nm}$ for compound 2 and at around 485, 517, and $553 \mathrm{~nm}$ for 3 . The first three components are in good agreement with the values obtained experimentally at low temperature (see Figure 2) at 490, 510 and $548 \mathrm{~nm}$ for $\mathbf{2}$ and at 502, 526 and $560 \mathrm{~nm}$ for 3.

As is usually observed with conjugated polymers and small molecules, the most intense component that contributes to the vibronic progression comes from modes at 1000 $1500 \mathrm{~cm}^{-1}$ which correspond to skeletal $\mathrm{C}=\mathrm{C} / \mathrm{C}-\mathrm{C}$ stretching modes and that thus impart a strong electron- vibrational coupling. In the case of linearly connected oligothiophenes and dioxides oligothiophenes, there is an additional type of low frequency vibrational mode, between $600-300 \mathrm{~cm}^{-1}$, that also contribute to the vibronic progressions. These modes are due to out-of-plane deformation vibrations, or torsional modes, which are absent in the investigated fused thienoacene dioxide compounds.

Another important aspect pointed out by theory is that the first excited state is associated with a HOMO to LUMO transition with transition dipole moment along the long molecular axis Thus, the alignment of molecules $\mathbf{1}$ and $\mathbf{2}$ or $\mathbf{3}$ along the long and short molecular axis would favour the energy transfer between the two molecules. Molecule $\mathbf{2}$ has a 
Submitted to

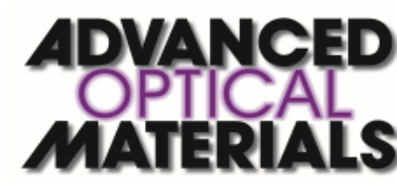

dipole moment along the short molecular axis, just like molecule 1, whereas molecule $\mathbf{3}$ has a small component of the dipole moment along the short molecular axis as well (Figure S1). From the electrostatic point of view, molecules $\mathbf{1}$ and $\mathbf{2}$ would prefer to stay one aligned with respect to the other, whereas molecules $\mathbf{1}$ and $\mathbf{3}$ would have a small twist to minimize the energy of the dipole-dipole interaction. Hence, this electrostatic coupling reinforces the formation of dimers and drives a relative orientation of the two molecules suitable for energy exchange.

3.3. Transient triplet-triplet absorption spectra. The transient triplet-triplet data obtained by laser flash photolysis shown in Figure 5 for compounds 1, 2 and $\mathbf{3}$ exhibit both band bleach between 300 and $400 \mathrm{~nm}$ and excited state absorption between 400 and $700 \mathrm{~nm}$, attributed to ground state depletion and triplet excited state population, respectively.
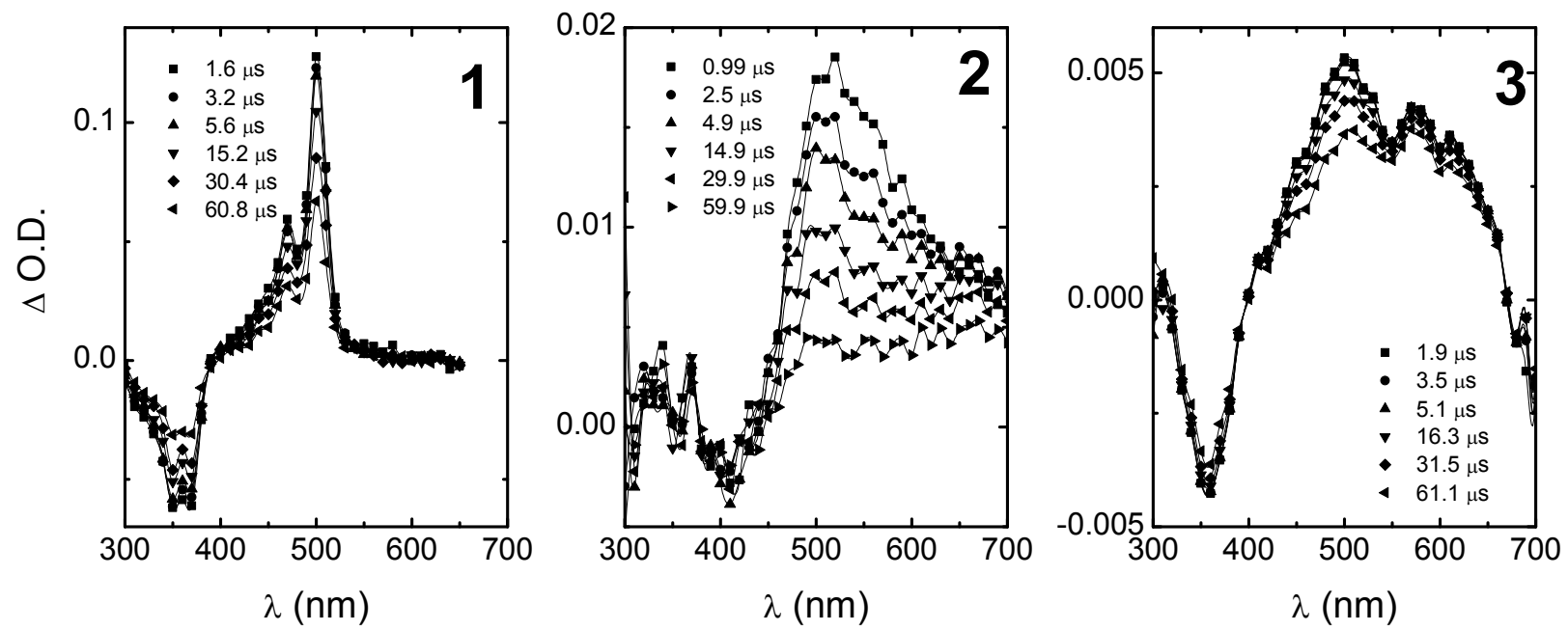

Figure 5. Transient triplet-triplet absorption spectra collected with different time delay after flash (indicated in the inside box of each plot) for $\mathbf{1}, \mathbf{2}$ and $\mathbf{3}$ in ethanol at $293 \mathrm{~K}$.

The transient spectrum of $\mathbf{1}$ is vibronically resolved, a well-known characteristic of rigid aromatic structures. In contrast to $\mathbf{1}$, for compounds $\mathbf{2}$ and $\mathbf{3}$, the transient triplet-triplet (i.e., $\mathrm{T}_{1} \rightarrow \mathrm{T}_{\mathrm{n}}$ ) absorption spectra are broad and unstructured. The increased broadening suggests that sulfonation leads to less localized triplet states in $\mathbf{2}$ and $\mathbf{3}$. Likely, the charge 
transfer character of the $T_{1} \rightarrow T_{n}$ excitations involving the oxidized ring might result in less structured spectra. Although spectral broadening precludes an accurate determination of their wavelength position, the main components for the three samples appear at around $500 \mathrm{~nm}$ and slightly red-shift from $\mathbf{1} \rightarrow \mathbf{2} \rightarrow \mathbf{3}$ in accordance with the red-shift in the PL spectra due to the energy stabilizing effect of the $\mathrm{SO}_{2}$ group in the LUMO energies.

For 2 and 3, the fluorescence spectra (Figure 2) and the transient triplet-triplet absorption spectra (Figure 5) clearly coincide in the wavelength region from 450 to $650 \mathrm{~nm}$. Given that stimulated emission will take place within the fluorescence emission spectral range, absorption by the triplet species might withdraw laser performance. On the other hand, for compound $\mathbf{1}$ there is practically no overlap of the spectra, given that fluorescence appears at shorter wavelengths $(370-420 \mathrm{~nm}) .^{36}$ The influence of the triplet absorptions on the ASE performance of the various compounds will be discussed below (section 3.5).

Table 2-Spectroscopic (molar extinction coefficients, $\varepsilon_{\mathrm{T}}$ ) and photophysical parameters [quantum yields $\left(\phi_{\mathrm{IC}}, \phi_{\mathrm{T}}\right.$ and rate constants $\mathrm{k}_{\mathrm{IC}}$ and $\mathrm{k}_{\mathrm{ISC}}$ ) for compounds $\mathbf{1 - 3} \mathrm{in}$ THF and ethanol at room temperature (293 $\left.\mathrm{K}\right)$. $\phi_{\Delta}$ is the quantum yield of sensitized singlet oxygen formation.

\begin{tabular}{|c|c|c|c|c|c|c|}
\hline & $\varepsilon_{\mathrm{T}}\left(\mathrm{M}^{-1} \mathrm{~cm}^{-1}\right)$ & $\phi_{\mathrm{T}}$ & $\phi_{\Delta}$ & $\phi_{\text {IC }}$ & $\mathrm{k}_{\mathrm{lc}} / \mathrm{ns}^{-1}$ & $\mathrm{k}_{\mathrm{Isc}} / \mathrm{ns}^{-1}$ \\
\hline \multirow{2}{*}{1 (THF) } & \multirow{2}{*}{55417 (a) } & \multirow{2}{*}{0.43 (b) } & \multirow{2}{*}{$0.39(\mathrm{c})$} & \multirow{2}{*}{0.33} & $3.3^{*}$ & $4.3^{*}$ \\
\hline & & & & & $0.825^{* *}$ & $1.075^{* *}$ \\
\hline \multirow{2}{*}{$1(\mathrm{EtOH})$} & \multirow{2}{*}{19712 (a) } & \multirow{2}{*}{0.67 (b) } & \multirow{2}{*}{$0.26(\mathrm{c})$} & \multirow{2}{*}{0.17} & 0.850 & 3.350 \\
\hline & & & & & 0.425 & 1.675 \\
\hline \multicolumn{7}{|l|}{2 (THF) } \\
\hline $2(\mathrm{EtOH})$ & 18080 (a) & $0.045(b)$ & & & & \\
\hline 3 (THF) & 22430 (a) & $0.17(b)$ & 0.17 (c) & 0.01 & 0.00153 & 0.0261 \\
\hline $3(\mathrm{EtOH})$ & 11733 (a) & $0.16(b)$ & $0.145(\mathrm{c})$ & 0.03 & 0.00374 & 0.0199 \\
\hline
\end{tabular}

* obtained using the major component value of a biexponential decay; see Table 1.

** obtained using the major component value at $410 \mathrm{~nm}$ of a biexponential decay; see Table 1.

(a) Donor: Naphthalene ( []$\left.=2 \times 10^{-4} \mathrm{M}, \varepsilon_{\mathrm{T}}=24500\right)$

(b) Reference used: Benzophenone in benzene $\left(\phi_{T}=1, \varepsilon_{T}=7200\right)$; see experimental section for further details.

(c) Reference used: $1 \mathrm{H}$-Phenalen-1-one in Toluene $\left(\phi_{\Delta}=0.93\right)$ ); see experimental section for further details. 


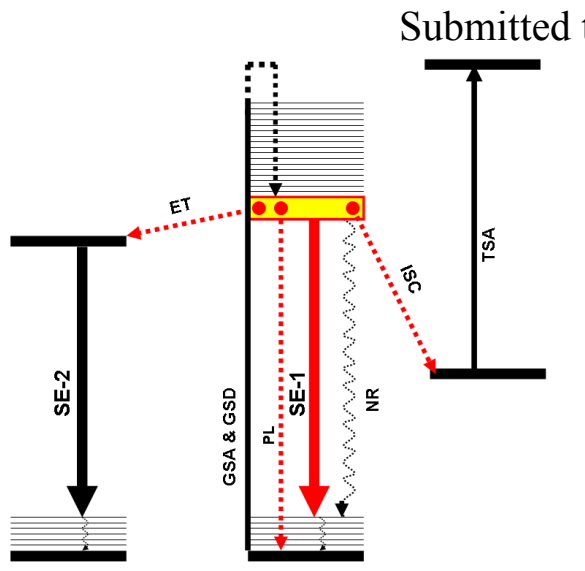

Scheme 1. Jablonski's-type diagram representing in red the main molecular photophysical processes competing with SE: stimulated emission; ISC: intersystem crossing; PL: photoluminescence; GSA \& GSD: ground state absorption and ground state depletion; ET: energy transfer; NR: non-radiative processes; TSA: triplet state absorption.

From the transient triplet-triplet spectra (Figure 5) the relevant photophysical parameters associated to the triplet states were obtained: triplet absorption strength $\left(\varepsilon_{\mathrm{T}}\right)$, triplet quantum yield $\left(\phi_{\mathrm{T}}\right)$, sensitized singlet oxygen formation $\left(\phi_{\Delta}\right)$, and rate constant for inter-system crossing, defined as $\mathrm{k}_{\mathrm{ISC}}=\phi_{\mathrm{T}} / \tau_{\mathrm{F}}$. Additional parameters, calculated with these values and with those obtained in section 3.1 for the singlet states, have also been included: internal conversion quantum yield $\left(\phi_{\mathrm{IC}}=1-\phi_{\mathrm{F}}-\phi_{\mathrm{T}}\right)$ and rate constant $\left(\mathrm{k}_{\mathrm{IC}}=\phi_{\mathrm{IC}} / \tau_{\mathrm{F}}\right)$. These data are collected in Table 2 and will be discussed in the context of the ASE performance in next sections. Together with ASE, Scheme 1 shows a Jablonski diagram with the relevant processes discussed in this work.

3.4. Energy transfer in solution: Stern-Volmer plots. Figure 6 shows the fluorescence emission spectra of THF solutions containing $\mathbf{1}+\mathbf{2}$ and $\mathbf{1}+\mathbf{3}$ for different concentrations of the sulfonated samples. It is noticed that the emission bands of $\mathbf{2}$ and $\mathbf{3}$ increase their intensity at the expenses of the decrease on the emission of $\mathbf{1}$, a quenching process that is found more extensive by increasing the concentration of the sulfonated compounds. This means that upon excitation of $\mathbf{1}, \mathbf{1} \rightarrow \mathbf{2}$ and $\mathbf{1} \rightarrow \mathbf{3}$ energy transfer mechanisms (i.e., ET in Scheme 1) act, which 
are explained by the spectral overlap of the emission spectra of $\mathbf{1}$ and the absorption spectra of 2 and 3. In addition, the efficiency of the ET depends on the relative concentration of the twocomponent mixtures, indicating the bimolecular nature of the energy transfer process.
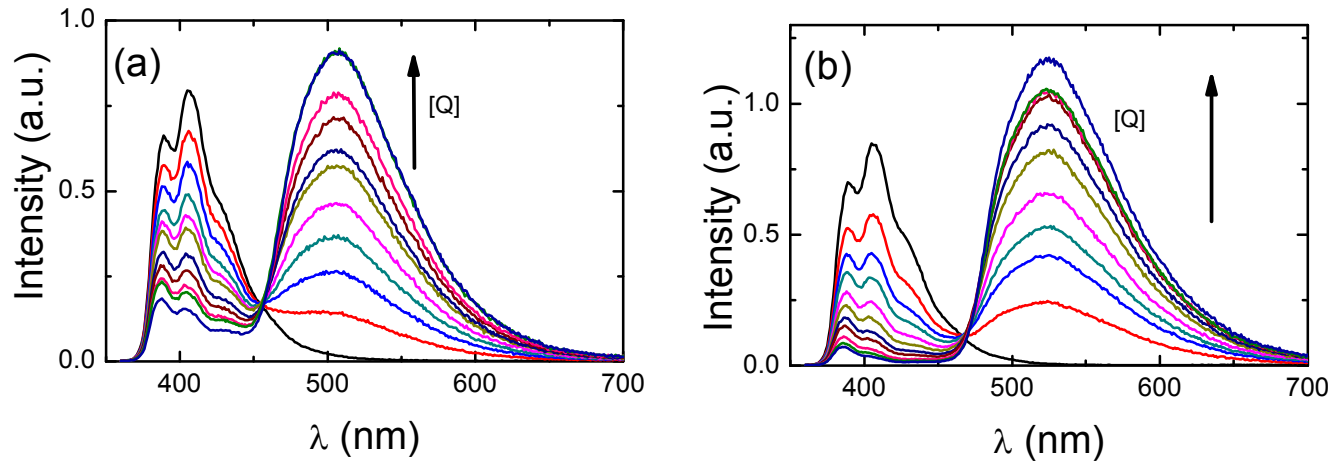

Figure 6. Fluorescence emission spectra of $\mathbf{1}+\mathbf{2}$ (a) and $\mathbf{1}+\mathbf{3}$ (b) mixtures in THF at different concentrations of quencher $(\mathrm{Q}=\mathbf{2}$ or $\mathbf{3})$ obtained by excitation in the absorption maxima of $\mathbf{1}$.

To explore these ET mechanisms, Stern-Volmer plots have been also represented and the relevant parameters derived (see Supporting Information). Stern-Volmer constants $\left(K_{\mathrm{sv}}=\right.$ $\left.k_{\mathrm{q}} \cdot \tau_{0}\right)$ of $34930 \mathrm{M}^{-1}$ and $45918 \mathrm{M}^{-1}$ were obtained for $\mathbf{1}+\mathbf{2}$ and $\mathbf{1}+\mathbf{3}$, respectively. Then, by using the fluorescence lifetime of $\mathbf{1}$ in the absence of the quenchers $\mathbf{2}$ and $\mathbf{3}$ ( $\tau_{0}=0.1 \mathrm{~ns}$, see Table 1), $k_{\mathrm{q}}$ values of $3.5 \times 10^{14} \mathrm{M}^{-1} \mathrm{~s}^{-1}$ and $4.6 \times 10^{14} \mathrm{M}^{-1} \mathrm{~s}^{-1}$ for compounds 2 and $\mathbf{3}$ were calculated respectively. The magnitude of these quenching rate constants is considerably larger than those expected for processes controlled by diffusion $\left(10^{9}-10^{10} \mathrm{~s}^{-1}\right)$. This strongly suggests the presence of ground-state interaction between $\mathbf{1}$ and $\mathbf{2}$ and between $\mathbf{1}$ and $\mathbf{3}$. A similar behavior has been previously found with the system consisting in the organic conjugated poly\{1,4-phenylene-[9,9-bis(4-phenoxy-butylsulfonate)]fluorene-2,7-diyl\} copolymer and the quencher tris(bipyridyl)ruthenium(II). ${ }^{54}$ These high values of the SternVolmer constants are in line with the quantum chemical calculations in section 3.2 in three main concerns: i) Simulations anticipate the formation of robust dimers due to the suitable coupling between the ground state dipoles, either in $\mathbf{1}+\mathbf{2}$ and in $\mathbf{1}+\mathbf{3}$; ii) The relative orientation of the dipoles in each subunit is very adequate for energy transfer since the 
Submitted to

transmission of the excitation from $\mathbf{1}$ to $\mathbf{2} / \mathbf{3}$ might give rise to large variations of the transition dipole-dipole momenta; iii) In addition, we have calculated the absorption and emission spectra of $\mathbf{1}$ and compare them with the theoretical absorption profiles of $\mathbf{2}$ and $\mathbf{3}$ such as shown in Figure 7. These simulations support that $\mathbf{1}$ can be used as an absorber for $\mathbf{2}$ and $\mathbf{3}$, delivering energy through its emission spectrum. Both $\mathbf{2}$ and $\mathbf{3}$ absorption spectra have good spectral overlap with the emission spectrum of $\mathbf{1}$ as observed in the experiments.

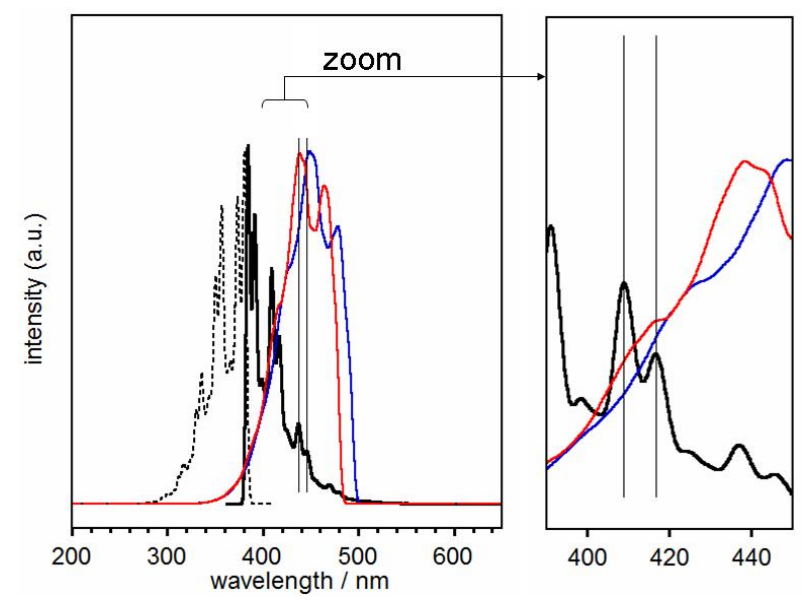

Figure 7. Theoretical absorption (dotted line) and emission (full line) of $\mathbf{1}$ (black) together with the absorption of 2 (red) and 3 (blue). Each theoretical transition (stick transition) was represented by a Gaussian with FWHM equal to $300 \mathrm{~cm}^{-1}$.

The condition of spectral overlap for the occurrence of energy transfer is a conservation energy requirement, which is rather independent of the particular type of interaction between the interacting molecules. Due to the microscopic description of the energy exchange in well formed $\mathbf{1}+\mathbf{2}$ and $\mathbf{1}+\mathbf{3}$ dimers, the ET mechanism might be governed by vibrational overlap as well, which invokes that for the efficiency of the ET process there should exist overlap of particular vibronic transitions in the two molecules due similar vibrational modes (i.e., frequency resonances) in the excited state of the donor and on the ground state of the acceptor. We deduce on the existence of vibrational overlap of 1 with either $\mathbf{2}$ or $\mathbf{3}$ between the vibronic peak at $435 \mathrm{~nm}$ in $\mathbf{1}$ and 440 for $\mathbf{2}$ and $450 \mathrm{~nm}$ for $\mathbf{3}$ (see Figure 7). 
These factors strongly highlight the particular conditions needed to be fulfilled to have efficient ET between distinct chromophores. According to the results obtained from the SternVolmer plots, it is seen that the quenching of the emission of $\mathbf{1}$ by $\mathbf{3}$ is more efficient than by

2. In this regard, we must point out that when the quencher concentration increases (see Figure 6) the emission of 1 not only progressively decreases but also its spectral profile changes as well. In particular when the concentration of the quencher, [Q], 2/3 is small the $0-1$ peak of emission from 1 dominates; however at high [Q], the 0-0 vibronic emission peak of $\mathbf{1}$ in the two $\mathbf{1}+\mathbf{2}$ and $\mathbf{1}+\mathbf{3}$ cases prevails. These are clear indications of the existence of light reabsorption by $\mathbf{1}$ when [Q] is small and that re-absorption is mitigated at high [Q]. Nevertheless, this effect is almost completely absent in $\mathbf{1}+\mathbf{3}$ while in $\mathbf{1}+\mathbf{2}$ it still occurs even at the highest [Q]. Since re-absorption withdraws emitted photons, this effect might affect much more negatively to $\mathbf{1}+\mathbf{2}$ than $\mathbf{1}+\mathbf{3}$, which could account for the difference between their $K_{\mathrm{sv}}$.

\subsection{Films containing either 2 or 3: Absorption, fluorescence and ASE under direct} optical excitation. Absorption and fluorescence spectra for films containing $10 \mathrm{wt} \%$ of either $\mathbf{2}$ or $\mathbf{3}$ are displayed in Figure 8.
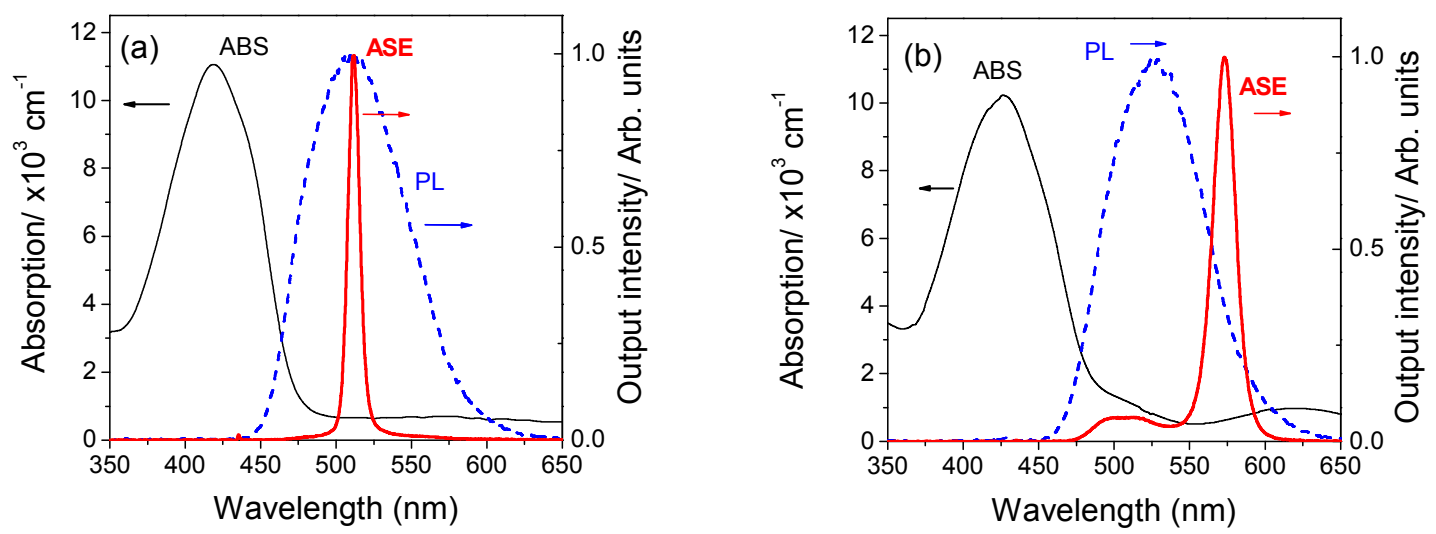

Figure 8. Absorption (ABS, left axis, thin solid line), photoluminescence emission (PL, right axis, dashed line) and ASE under excitation at $\lambda_{\mathrm{ex}}=435 \mathrm{~nm}$ (right axis, thick solid line) spectra of films doped with $10 \mathrm{wt} . \%$ of either 2 (a) or 3 (b) 
Submitted to

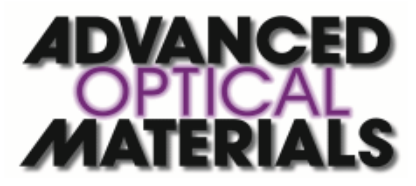

Various optical parameters determined from them are listed in Table 3. It is interesting to compare these spectra to those obtained in solution at RT (Figure 2). In general in films the shape of both the absorption and the fluorescence spectra are similar. Minor red-shifts values of around $5 \mathrm{~nm}$ are observed in the films spectra with respect to those obtained in solution. It is remarkable the appearance of some absorption in the region between 500 and $520 \mathrm{~nm}$ in the film doped with $\mathbf{3}$, which is not present in the spectrum in solution. Such absorption is not observed in the spectrum of the film containing 2. Although the origin of this absorption is not clear at the moment, a possibility would be that it is related to the type of molecular arrangement in the films, that might be different for each compound. This is further supported by calculations which predict the dipoles of $\mathbf{2}$ and $\mathbf{3}$ to have different orientations which would conduct different intermolecular packing.

Table 3. Absorption, fluorescence and ASE parameters for PS films doped with different compounds.

\begin{tabular}{|c|c|c|c|c|c|c|c|c|c|}
\hline Comp. & $\begin{array}{l}\text { Conc. } \\
(\% \mathrm{wt})\end{array}$ & $\begin{array}{r}\lambda_{\text {ex }} \\
(\mathrm{nm})\end{array}$ & $\begin{array}{c}\lambda_{\mathrm{abs}}^{\max } \\
(\mathrm{nm})\end{array}$ & $\begin{array}{l}\alpha\left(\lambda_{\text {abs }}^{\max }\right) \\
\left(\times 10^{3} \mathrm{~cm}^{-1}\right)\end{array}$ & $\begin{array}{c}\alpha\left(\lambda_{\mathrm{ex}}\right) \\
\left(\times 10^{3} \mathrm{~cm}^{-1}\right)\end{array}$ & $\begin{array}{c}\lambda_{\mathrm{PL}}^{\max } \\
(\mathrm{nm})\end{array}$ & $\begin{array}{l}\lambda_{\mathrm{ASE}} \\
(\mathrm{nm})\end{array}$ & $\begin{array}{c}\text { FWHM }_{\text {ASE }} \\
(\mathrm{nm})\end{array}$ & $\begin{array}{c}I_{\mathrm{th}} \\
\left(\mathrm{kW} \cdot \mathrm{cm}^{-2}\right)\end{array}$ \\
\hline $1 *$ & 10 & 355 & 359 & 23.72 & 21.36 & 413 & 414 & 5 & 10 \\
\hline 2 & 10 & 435 & 420 & 11.10 & 9.73 & 510 & 511 & 9 & 24 \\
\hline 3 & 10 & 435 & 427 & 10.23 & 9.82 & 525 & 573 & 13 & 75 \\
\hline $1: 2$ & $10: 10$ & 355 & & & & & 519 & 39 & $>1000$ \\
\hline $1: 3$ & $10: 11$ & 355 & & & & & 573 & 19 & 37 \\
\hline
\end{tabular}

In order to evaluate the laser capability of films doped with either $\mathbf{2}$ or $\mathbf{3}$, these were excited, as described in the experimental section, at the $435 \mathrm{~nm}$ wavelength, which matches their absorption bands. A drastic decrease in the spectral emission linewidth, above a certain pump intensity (the threshold), due to ASE, was observed in both cases. This is illustrated in Figure 8, which shows the ASE spectra, obtained at pump intensities of $46 \mathrm{~kW} \cdot \mathrm{cm}^{-2}$ and 190 $\mathrm{kW} \cdot \mathrm{cm}^{-2}$ for films doped with $\mathbf{2}$ and $\mathbf{3}$ respectively. The characteristic ASE parameters, i.e. 
threshold $\left(I_{\text {th-ASE }}\right)$-defined as the intensity at which the emission linewidth decays to half of its maximum value-; -; linewidth - defined as the full width at half of the maximum, FWHM- above threshold (FWHM $\mathrm{ASE})$; and emission wavelength $\left(\lambda_{\mathrm{ASE}}\right)$, are listed in Table 3. For comparison purposes, data for films doped with 10 wt. \% of compound 1, already reported in ref. 12, have also been included.

By comparing Figures 8(a) and 8(b), a first difference is that ASE takes place at a rather different wavelength in comparison with the photoluminescence spectra. For the film doped with 2, ASE appears at around $511 \mathrm{~nm}$, coincident with the peak of maximum intensity in the PL spectrum of the film. As described in sections 3.1 and 3.2., this peak corresponds to most intense vibrational component of the PL (the 0-1), which appears at $510 \mathrm{~nm}$ in the low temperature spectrum shown in Fig. 2a. On the other hand, for the film doped with $\mathbf{3}$, ASE appears at $573 \mathrm{~nm}$, clearly red-shifted with respect to the maximum of its PL spectrum, observed at $525 \mathrm{~nm}$, which corresponds to the 0-1 component of the PL spectrum measured at low temperature (see Figure 2b). The $573 \mathrm{~nm}$ wavelength at which ASE appears seems to correspond with the $0-2$ vibrational component predicted theoretically at $575 \mathrm{~nm}$ (see Figure 4) and observed experimentally at low temperature at around $560 \mathrm{~nm}$ (Figure 2b).

In many materials investigated in the literature, ASE appears at the most intense vibronic transition. Very often this is the $0-1$ transition, given that the intensity of the $0-0$ component is reduced by self- or re-absorption due to the proximity between absorption and PL. ${ }^{15-18}$ That is also the case also for derivatives $\mathbf{1}^{36}$ and $\mathbf{2}$. Given that the relative intensities of the various PL components is the same for both compounds $\mathbf{2}$ and $\mathbf{3}$, the reason why for $\mathbf{3}$ ASE appears at the 0-2 PL transition, should be based on other processes. A first possibility would be the existence of triplet-triplet absorption in the region at which the 0-1 PL transition appears. Data shown in Figure 5 and in Table 2 indicate that triplet absorption in solution appears precisely in the spectral region at which ASE appears. However, the triplet molar 
extinction coefficient for compound $\mathbf{2}$ is larger than that of $\mathbf{3}$. Therefore, from a microscopic point of view triplet absorption does not seem to be the reason for the shift observed in the ASE emission of 3. At this point we recall that the absorption spectrum of the film doped with 3 shows some absorption precisely in the region of maximum PL, which is not present in the spectrum of the film containing 2 . This might be responsible for the losses at this wavelength that forces the ASE emission to shift to the red. Other possible explanation would be the presence of excited state absorption, which might be stronger for $\mathbf{3}$ than for $\mathbf{2}$. In the case of $\mathbf{1}$, the triplet molar extinction coefficient is around twice that of 3. However, PL emission and ASE take place at lower wavelengths, so they do not practically overlap with triplet absorption.

Concerning the ASE thresholds, values for $\mathbf{2}$ and $\mathbf{3}$ are larger than those obtained for the non-oxidized derivative $\mathbf{1}$. For the film doped with $\mathbf{2}, I_{\text {th-ASE }}$ is 2.4 times higher than the one for the film containing $\mathbf{1}$. For compound $\mathbf{3}$, the difference is even larger ( 7.5 times higher). In order to understand these results various photophysical parameters should be considered: singlet molar extinction coefficient $\left(\varepsilon_{\mathrm{s}}\right)$, film absorption coefficient at the excitation wavelength $\left(\alpha\left(\lambda_{\text {ex }}\right)\right)$, fluorescence quantum yields $\left(\phi_{\mathrm{F}}\right)$, triplet absorption coefficients $\left(\varepsilon_{\mathrm{T}}\right)$ and film absorption and PL intensity at the wavelength at which ASE takes place. Firstly, as observed in Table 3, $\alpha\left(\lambda_{\text {ex }}\right)$ in the film doped with $\mathbf{1}$ is around twice that of films based on $\mathbf{2}$ or 3. This difference is mainly due to the higher singlet molar extinction coefficient of $\mathbf{1}$ (see Table 1), but also to a better matching between $\lambda_{\text {ex }}$ and the wavelength of maximum absorption $\left(\lambda_{\mathrm{abs}}{ }^{\max }\right)$. It should be noted that the absorption coefficients listed in Table 3 are calculated at a certain wavelength, i.e., $\lambda_{\mathrm{ex}}$, while $\varepsilon$ is computed as the area integrated under the spectrum. Secondly, $\phi_{\mathrm{F}}$ for $\mathbf{1}$ is around three times lower than that of $\mathbf{2}$ and $\mathbf{3}$. So if this parameter were the dominant one, the $I_{\text {th-ASE }}$ value for $\mathbf{1}$ should be larger. Concerning triplet absorption, as already mentioned, it overlaps with the region were PL emission appears for 
compounds $\mathbf{2}$ and $\mathbf{3}$, but not for $\mathbf{1}$. So, this would also explain the lower ASE thresholds measured in 1, despite its lower PL efficiency. Finally, another factor that might play a role in the threshold is the fluorescence lifetime. For compound $\mathbf{1}, \tau_{\mathrm{F}}$ is clearly shorter than the duration of the excitation pulses ( $0.1 \mathrm{~ns}$ versus $10 \mathrm{~ns})$, so steady-state conditions apply. On the other hand, for compounds $\mathbf{2}$ and $\mathbf{3}, \tau_{\mathrm{F}}$ is very similar to the length of pump pulses, so the creation of population inversion might be less optimized. The combination of all these parameters, explain the higher ASE thresholds measured for the oxidized compounds, as compared to that of the non-oxidized derivative. However, they cannot justify the differences encountered between $\mathbf{2}$ and $\mathbf{3}$, since all these parameters are similar. The higher threshold measured in $\mathbf{3}$ can be explain by the fact that ASE appears at a wavelength strongly redshifted from the maximum of its PL spectrum, at which the PL efficiency (and therefore the gain) is much lower.

Finally, the ASE linewidths are rather different for the various compounds, much shorter for compound $\mathbf{1}$ and larger for compound 3. This trend is in accordance with the fluorescence lifetime values, shorter for compound $\mathbf{1}\left(\tau_{\mathrm{F}}=0.10 \mathrm{~ns}\right)$ and larger for compounds $\mathbf{2}$ and $\mathbf{3}$ (5.3 and 6.8 ns respectively).

\subsection{Films containing 1 (host) and either 2 or 3 (guests): ASE assisted by energy transfer}

from host to guest. The capability to obtain energy transfer from 1 to either 2 or 3 in solution was demonstrated in section 3.4. So, we aimed to get profit from this energy transfer process and try to obtain ASE from $\mathbf{2}$ and $\mathbf{3}$, but exciting on the absorption band of $\mathbf{1}$, i.e. at a much lower wavelength than the one used when they are directly excited $(355 \mathrm{~nm}$, instead of 435 nm). Films containing 10 wt.\% of $\mathbf{1}$ and a varying amount (from 3 to 15 wt.\%) of 2 or 3 were prepared and their absorption and PL properties characterized. Energy transfer was observed 
in all cases, as evidenced by the observation of PL spectra similar to those obtained when $\mathbf{2}$ or 3 are excited directly on their absorption bands. Results are illustrated in Figure 9 for the samples containing 10 wt. $\%$ of either $\mathbf{2}$ or $\mathbf{3}$ (in addition to compound $\mathbf{1}$ ).
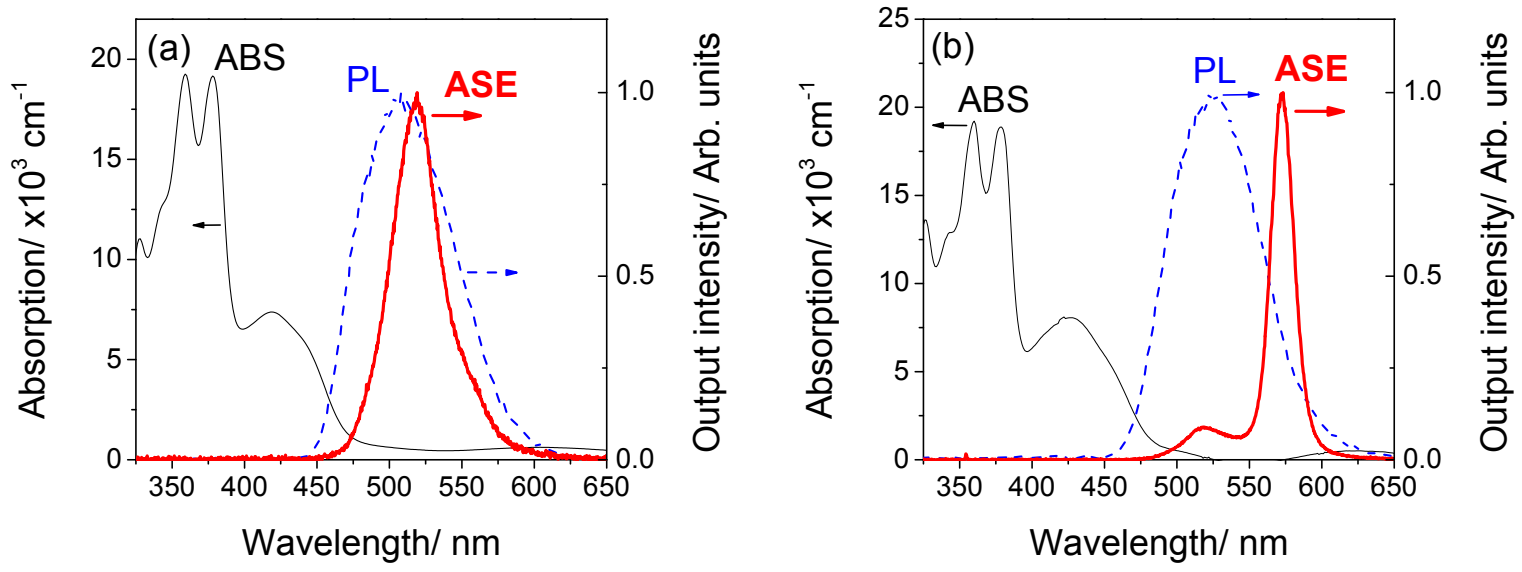

Figure 9. Absorption (ABS, left axis, thin solid line), photoluminescence emission (PL, right axis, dashed line) and ASE under excitation at $\lambda_{\text {ex }}=355 \mathrm{~nm}$ (right axis, thick solid line) for films containing $10 \mathrm{wt} \%$ of 1 (host) and 10 wt. $\%$ of $\mathbf{2}$ or $\mathbf{3}$, as guests (a and b, respectively).

Samples were also characterized in the ASE setup, under excitation at $355 \mathrm{~nm}$. When the pump intensity was increased, narrowing of the emission spectra was observed for both types of films (doped with either $\mathbf{2}$ or $\mathbf{3}$ ), indicating the presence of ASE (see Figure 9). For 1+2, the ASE thresholds and linewidths were fairly large $\left(I_{\text {th-ASE }}>1000 \mathrm{~kW} \cdot \mathrm{cm}^{-2}\right.$ and FWHM $_{\mathrm{ASE}} \sim 40 \mathrm{~nm}$, see Table 3). As a consequence of the large pump intensities needed to obtain ASE, samples degraded very quickly, preventing an accurate determination of these parameters. On the other hand, for samples containing $\mathbf{1 + 3}$, thresholds and linewidths were significantly lower $\left(I_{\text {th-ASE }}=37 \mathrm{~kW} \cdot \mathrm{cm}^{-2}\right.$ and $\mathrm{FWHM}_{\mathrm{ASE}}=19 \mathrm{~nm}$, see Table 3$)$. It is also remarkable that this threshold value is around two times smaller than the one obtained for the film containing only $\mathbf{3}$ and pumped directly. Therefore, in this case, the strategy of reducing the threshold by using energy transfer was successful. 
The observation that for the blends containing 3, the ASE process is more efficient than for those with $\mathbf{2}$, might be due to a more efficient energy transfer process from $\mathbf{1}$. This would be in accordance with the larger Stern-Volmer constants measured in solution for the system 1+3. However, the differences in the values of the constants for the two systems were not very significant, so probably other processes are responsible for this behaviour. One possibility is that triplet absorption contributes more in this case than when films are excited directly. Note that due to the energy transfer process, the duration of the overall process of excitation and ASE emission is much longer. As a consequence triplet states would get a larger population, thus resulting in a larger absorption. Given that for compound $\mathbf{3}$ ASE is shifted to the red, where triplet absorption is very weak, this would not be an issue. On the other hand, ASE in films containing 2 appears precisely in that spectral region. In addition, for $\mathbf{2}$ it is not possible to shift the emission to a region without triplet absorption, since its PL spectrum is blue shifted with respect to that of $\mathbf{3}$. Note that $\mathbf{2}$ does not show any vibrational PL peak close to the wavelength at which ASE for 3 is observed.

The ASE wavelengths and linewidths for the various films prepared did not practically change with the content of guest, thus values shown in Table 3 for the best performing blends are representative of all of them. It should also be noted that the ASE wavelength obtained for films containing 3 (around $573 \mathrm{~nm}$ ) is practically independent on the type of excitation, i.e. direct or through energy transfer. This is probably due to the fact that ASE in this compound appears at the long-wavelength edge of the PL spectrum, so it is not affected by selfabsorption. On the other hand, for films based on 2, the ASE wavelength is longer for the blends $\left(\lambda_{\mathrm{ASE}}=519 \mathrm{~nm}\right)$, in which ASE is assisted by energy transfer, than when $\mathbf{2}$ is the only active component in the film $\left(\lambda_{\mathrm{ASE}}=511 \mathrm{~nm}\right)$, and ASE is obtained by direct excitation. This red shift in $\lambda_{\mathrm{ASE}}$ observed in the blends might be indicative of strong self-absorption, presumably due to triplets. With respect to the ASE linewidths, it is remarkable the much 
larger values obtained with the blends, as compared to those of the samples pumped directly. Moreover, for the films containing 2, spectra are quite broad $\left(\mathrm{FWHM}_{\mathrm{ASE}}=39 \mathrm{~nm}\right)$, in contrast with the $\mathrm{FWHM}_{\mathrm{ASE}}=9 \mathrm{~nm}$ obtained for the film directly pumped. For films containing $\mathbf{3}$, although the linewidth is also larger in the blends than in the films pumped directly (19 and 13 $\mathrm{nm}$ respectively), the difference is much smaller. The larger linewidths obtained when ASE is obtained through energy transfer might be related to the longer lifetime of the emission process.

\section{Conclusions}

In this work we have extended the lasing photonic properties of dioxide oligothiophenes to the family of the dioxide thienoacenes. We have carried out a complete photophysical study including steady-state spectroscopy (absorption, photoluminescence and energy transfer) and kinetic analysis (fluorescence lifetimes, triplet-triplet transient absorption and energy transfer Stern-Volmer) of newly designed dioxide pentathienoacenes. All photophysical data have been directed to understand the dual ASE properties displayed by these dioxide thienoacene dyes and interpreted and supported with the help of quantum chemical calculation. On direct excitation regime, we have shown that ASE is observed at different wavelengths depending of the isomeric character (position of the dioxide group) and explained their efficiency in terms of the distinctive photophysic behaviour. As a second novelty we have probed lasing action mediated by energy transfer from a homologous nonoxidized compound which leads to improve the thresholds parameters on direct excitation, by more importantly, allows to broaden the laser wavelength spectrum (i.e., the laser colour) and to tune also the excitation energy spectrum, all achieved by a rather simple chemical modification of the thiophenic core. In general, the ASE properties discussed here represent bottleneck steps toward the development of lasing action exclusively involving organic dyes. 
Acknowledgment. Authors from the University of Alicante acknowledge support from the Spanish Government (MEC) and the European Community (FEDER) through grants MAT2008-06648-C02-01 and MAT2011-28167-C02-01. The work at the University of Málaga is supported by the MEC projects CTQ2009-10098 and by the PO9-4708 project by the Junta de Andalucía. Raquel Rondão acknowledges FCT for a PhD grant (SFRH/BD/38882/2007). D.A.S.F. gratefully acknowledges the financial support from the Brazilian Research Councils CNPq CAPES, CNPq (grant 303084/2010-3) and FAP-DF (Fundação de Apoio à Pesquisa do Distrito Federal).

\section{References}

(1) Fichou, D. Handbook of oligo- and polythiophenes; Wiley-VCH: Weinheim ; Chichester ; New York, 1999.

(2) Mishra, A.; Ma, C. Q.; Bauerle, P. Chem Rev 2009, 109, 1141.

(3) Perepichka, I. F.; Perepichka, D. F. Handbook of thiophene-based materials : applications in organic electronics and photonics; Wiley: Chichester, U.K., 2009.

(4) Roncali, J. Chem Rev 1997, 97, 173.

(5) Chernichenko, K. Y.; Sumerin, V. V.; Shpanchenko, R. V.; Balenkova, E. S.; Nenajdenko, V. G. Angew Chem Int Edit 2006, 45, 7367.

(6) Miyasaka, M.; Rajca, A.; Pink, M.; Rajca, S. J Am Chem Soc 2005, 127, 13806.

(7) Okamoto, T.; Kudoh, K.; Wakamiya, A.; Yamaguchi, S. Org Lett 2005, 7, 5301.

(8) Zhang, X. N.; Cote, A. P.; Matzger, A. J. J Am Chem Soc 2005, 127, 10502.

(9) Zhang, X. N.; Matzger, A. J. J Org Chem 2003, 68, 9813.

(10) Gao, J. H.; Li, R. J.; Li, L. Q.; Meng, Q.; Jiang, H.; Li, H. X.; Hu, W. P. Adv Mater 2007, 19, 3008.

(11) Xiao, K.; Liu, Y. Q.; Qi, T.; Zhang, W.; Wang, F.; Gao, J. H.; Qiu, W. F.; Ma, Y. Q.; Cui, G. L.; Chen, S. Y.; Zhan, X. W.; Yu, G.; Qin, J. G.; Hu, W. P.; Zhu, D. B. J Am Chem Soc 2005, 127, 13281.

(12) Zhang, X. N.; Johnson, J. P.; Kampf, J. W.; Matzger, A. J. Chem Mater 2006, 18,3470 .

(13) Yamada, K.; Okamoto, T.; Kudoh, K.; Wakamiya, A.; Yamaguchi, S.; Takeya, J. Appl Phys Lett 2007, 90, 072102.

(14) Kim, E. G.; Coropceanu, V.; Gruhn, N. E.; Sanchez-Carrera, R. S.; Snoeberger, R.; Matzger, A. J.; Bredas, J. L. J Am Chem Soc 2007, 129, 13072. 
(15) Tessler, N. Adv Mater 1999, 11, 363.

Submitted to

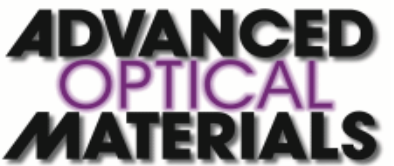

(16) McGehee, M. D.; Heeger, A. J. Adv Mater 2000, 12, 1655.

(17) Samuel, I. D. W.; Turnbull, G. A. Chem Rev 2007, 107, 1272.

(18) Grivas, C.; Pollnau, M. Laser Photonics Rev 2012, 6, 419.

(19) Duarte, F. J.; Hillman, L. W. Dye laser principles, with applications; Academic Press: Boston, 1990.

(20) Scholz, R.; Schreiber, M. Chem Phys 2006, 325, 9.

(21) Cornil, J.; Beljonne, D.; Calbert, J. P.; Bredas, J. L. Adv Mater 2001, 13, 1053.

(22) Yamagata, H.; Spano, F. C. J Chem Phys 2012, 136, 184901.

(23) McGehee, M. D.; Gupta, R.; Veenstra, S.; Miller, E. K.; Diaz-Garcia, M. A.; Heeger, A. J. Phys Rev B 1998, 58, 7035.

(24) Berggren, M.; Dodabalapur, A.; Slusher, R. E.; Bao, Z. Nature 1997, 389, 466.

(25) Kozlov, V. G.; Bulovic, V.; Burrows, P. E.; Forrest, S. R. Nature 1997, 389,

362.

(26) Gupta, R.; Stevenson, M.; Dogariu, A.; McGehee, M. D.; Park, J. Y.; Srdanov, V.; Heeger, A. J.; Wang, H. Appl Phys Lett 1998, 73, 3492.

(27) Anni, M.; Gigli, G.; Cingolani, R.; Zavelani-Rossi, M.; Gadermaier, C.; Lanzani, G.; Barbarella, G.; Favaretto, L. Appl Phys Lett 2001, 78, 2679.

(28) Pisignano, D.; Anni, M.; Gigli, G.; Cingolani, R.; Zavelani-Rossi, M.; Lanzani, G.; Barbarella, G.; Favaretto, L. Appl Phys Lett 2002, 81, 3534.

(29) Zavelani-Rossi, M.; Lanzani, G.; De Silvestri, S.; Anni, M.; Gigli, G.; Cingolani, R.; Barbarella, G.; Favaretto, L. Appl Phys Lett 2001, 79, 4082.

(30) Pisignano, D.; Persano, L.; Visconti, P.; Cingolani, R.; Gigli, G.; Barbarella, G.; Favaretto, L. Appl Phys Lett 2003, 83, 2545.

(31) Gigli, G.; Barbarella, G.; Favaretto, L.; Cacialli, F.; Cingolani, R. Appl Phys Lett 1999, 75, 439.

(32) Anni, M.; Gigli, G.; Paladini, V.; Cingolani, R.; Barbarella, G.; Favaretto, L.; Sotgiu, G.; Zambianchi, M. Appl Phys Lett 2000, 77, 2458.

(33) Gigli, G.; Inganas, O.; Anni, M.; De Vittorio, M.; Cingolani, R.; Barbarella, G.; Favaretto, L. Appl Phys Lett 2001, 78, 1493.

(34) Antolini, L.; Tedesco, E.; Barbarella, G.; Favaretto, L.; Sotgiu, G.; Zambianchi, M.; Casarini, D.; Gigli, G.; Cingolani, R. J Am Chem Soc 2000, 122, 9006.

(35) Della Sala, F.; Gigli, G.; Raganato, M. F.; Anni, M.; Pisignano, D.; Cingolani, R.; Favaretto, L.; Sotgiu, G.; Barbarella, G.; Antolini, L. Org Electron 2004, 5, 129.

(36) Navarro-Fuster, V.; Calzado, E. M.; Ramirez, M. G.; Boj, P. G.; Henssler, J. T.; Matzger, A. J.; Hernandez, V.; Navarrete, J. T. L.; Diaz-Garcia, M. A. J Mater Chem 2009, $19,6556$.

(37) Suzuki, Y.; Okamoto, T.; Wakamiya, A.; Yamaguchi, S. Org Lett 2008, 10, 3393.

(38) Becker, R. S.; Seixas de Melo, J.; Maçanita, A. L.; Elisei, F. J. Phys. Chem. 1996, $100,18683$.

(39) Pina, J.; Seixas de Melo, J. Phys. Chem. Chem. Phys. 2009, 11, 8706-8713.

(40) Striker, G.; Subramaniam, V.; Seidel, C. A. M.; Volkmer, A. J. Phys. Chem. B 1999, 103, 8612 .

(41) Becke, A. D. J Chem Phys 1993, 98, 5648.

(42) Lee, C. T.; Yang, W. T.; Parr, R. G. Phys Rev B 1988, 37, 785.

(43) Francl, M. M.; Pietro, W. J.; Hehre, W. J.; Binkley, J. S.; Gordon, M. S.; Defrees, D. J.; Pople, J. A. J Chem Phys 1982, 77, 3654.

(44) Harihara, P. C.; Pople, J. A. Theor. Chim. Acta 1973, 28, 213. 
(45) Hehre, W. J.; Ditchfie.R; Pople, J. A. J Chem Phys 1972, 56, 2257.

(46) Frisch, M. J.; Trucks, G. W.; Schlegel, H. B.; Scuseria, G. E.; Robb, M. A.; Cheeseman, J. R.; Scalmani, G.; Barone, V.; Mennucci, B.; Petersson, G. A.; Nakatsuji, H.; Caricato, M.; Li, X.; Hratchian, H. P.; Izmaylov, A. F.; Bloino, J.; Zheng, G.; Sonnenberg, J. L.; Hada, M.; Ehara, M.; Toyota, K.; Fukuda, R.; Hasegawa, J.; Ishida, M.; Nakajima, T.; Honda, Y.; Kitao, O.; Nakai, H.; Vreven, T.; Montgomery, J. A.; Peralta, J. E.; Ogliaro, F.; Bearpark, M.; Heyd, J. J.; Brothers, E.; Kudin, K. N.; Staroverov, V. N.; Kobayashi, R.; Normand, J.; Raghavachari, K.; Rendell, A.; Burant, J. C.; Iyengar, S. S.; Tomasi, J.; Cossi, M.; Rega, N.; Millam, J. M.; Klene, M.; Knox, J. E.; Cross, J. B.; Bakken, V.; Adamo, C.; Jaramillo, J.; Gomperts, R.; Stratmann, R. E.; Yazyev, O.; Austin, A. J.; Cammi, R.; Pomelli, C.; Ochterski, J. W.; Martin, R. L.; Morokuma, K.; Zakrzewski, V. G.; Voth, G. A.; Salvador, P.; Dannenberg, J. J.; Dapprich, S.; Daniels, A. D.; Farkas; Foresman, J. B.; Ortiz, J. V.; Cioslowski, J.; Fox, D. J. Wallingford CT, 2009.

5,540 .

(47) Barone, V.; Bloino, J.; Biczysko, M.; Santoro, F. J Chem Theory Comput 2009,

(48) Bloino, J.; Biczysko, M.; Crescenzi, O.; Barone, V. J Chem Phys 2008, 128.

(49) Pina, J.; Burrows, H. D.; Becker, R. S.; Dias, F. B.; Maçanita, A. L.; Seixas de Melo, J. J. Phys. Chem. B 2006, 110, 6499.

(50) Pina, J.; Seixas de Melo, J.; Burrows, H. D.; Bilge, A.; Farrell, T.; Forster, M.; Scherf, U. J. Phys. Chem. B 2006, 110, 15100.

(51) Bensasson, R. V.; Land, E. J.; Truscott, T. G. Excited states and free radicals in biology and medicine; Oxford Science Publications: Oxford, 1993.

(52) Murov, S.; Charmichael, I.; Hug, G. L. Handbook of Photochemistry; M. Dekker Inc.: New York, 1993.

(53) Coropceanu, V.; Cornil, J.; da Silva, D. A.; Olivier, Y.; Silbey, R.; Bredas, J. L. Chem Rev 2007, 107, 2165.

(54) Burrows, H. D.; Fonseca, S. M.; Dias, F. B.; Seixas de Melo, J.; Monkman, A. P.; Scherf, U.; Pradhan, S. Adv Mater 2009, 21, 1155. 


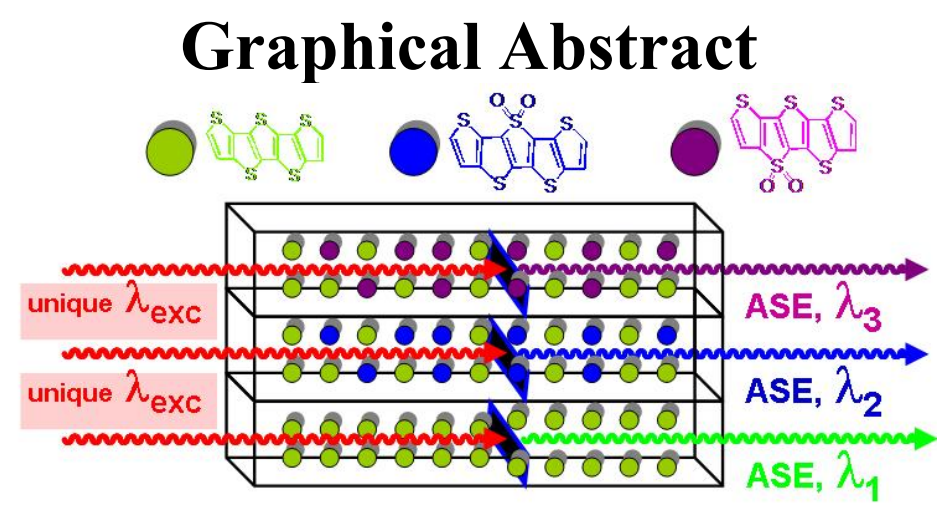




\section{SUPPLEMENTARY MATERIAL}

\section{Amplified Spontaneous Emission in Pentathienoacene Dioxides by Direct Optical Pump and by Energy Transfer: Correlation with Photophysical Parameters}

Juan Casado ${ }^{1}$, Víctor Hernández ${ }^{1}$, Juan T. López Navarrete ${ }^{* 1}$, Manuel Algarra ${ }^{2}$, Demetrio A. da Silva Filho ${ }^{3}$, Shigehiro Yamaguchi ${ }^{4}$, Raquel Rondão, ${ }^{5}$ J. Sergio Seixas de Melo, ${ }^{5}$ Victor Navarro-Fuster ${ }^{6}$, Pedro G. Boj, ${ }^{7}$ María A. Díaz-García*6

${ }^{1}$ Department of Physical Chemistry, University of Málaga, Campus de Teatinos s/n, Málaga 29071, Spain

${ }^{2}$ Centro de Geología, Departamento de Geociencias, Ambiente e Ordenamento do Território do Porto, Faculty of Science, University of Porto, Rua do Campo Alegre, 687, 4169-007 Porto, Portugal.

${ }^{3}$ Institute of Physics, University of Brasilia, 04455, DF, 70919-970, Brazil

${ }^{4}$ Department of Chemistry, Graduate School of Science, Nagoya University, Chikusa, Nagoya, Japan

${ }^{5}$ Department of Chemistry, University of Coimbra, P3049-535 Coimbra, Portugal

${ }^{6}$ Dpto. Física Aplicada and Instituto Universitario de Materiales de Alicante, Alicante 03080, Spain

${ }^{7}$ Dpto. Óptica and Instituto Universitario de Materiales de Alicante, Alicante 03080, Spain

*To whom correspondence should be addressed. E-mail: (J.C.) casado@uma.es, (M.A.D-G) maria.diaz@ua.es

\section{Experimental Details.}

The intersystem crossing yields for the compounds $\left(\phi_{\mathrm{T}}\right)$ were obtained by comparing the $\Delta \mathrm{OD}$ (optical density change) at $525 \mathrm{~nm}$ of benzene solutions of the compound and of benzophenone, used as standard $\left(\phi_{\mathrm{T}}=1\right.$ in benzene $\left.{ }^{[7]}\right)$, using the equation: ${ }^{[8]}$

$$
\phi_{T}^{\text {Compound }}=\frac{\varepsilon_{T T}^{\text {Benzophenone }}}{\varepsilon_{T T}^{\text {Compound }}} \cdot \frac{\Delta O D_{\max }^{\text {Compound }}}{\Delta O D_{\max }^{\text {Benzophenone }}} \cdot \phi_{T}^{\text {Benzophenone }}
$$


Experimental data were fitted with the Stern-Volmer equation given by:

$$
\frac{I_{0}}{I}=1+\underbrace{k_{q} \tau_{0}}_{K_{S V}}[Q]
$$

where $I_{0}$ is the initial intensity of fluorescence emission (without quencher), $I$ is the intensity of fluorescence emission after each addition of quencher, $\mathrm{k}_{\mathrm{q}}$ is quenching rate constant, $\tau_{0}$ is the fluorescence lifetime of the initial compound in the absence of quencher and [Q] is the concentration of the quencher.

\section{Theoretical Details.}

Geometry optimizations of the $\mathrm{S}_{0}$ state were computed using Density Functional Theory with the B3LYP functional and $6-31 \mathrm{G}^{* *}$ basis set, as implemented in Gaussian 09. The default criteria for SCF and geometry convergency was used. For the $\mathrm{S}_{1}$ state, Time Dependent Density Functional Theory was used with the same basis set and functional. The normal modes were saved to generate the vibronically resolved absorption $\mathrm{S}_{0} \rightarrow \mathrm{S}_{1}$ and emission $\mathrm{S}_{1} \rightarrow \mathrm{S}_{0}$ spectrum. These spectra were computed using a new functionally of the Gaussian 09 program suite. For both the absorption and emission spectra the stick transitions were convoluted with Gaussians with FHWM

equal to $300 \mathrm{~cm}^{-1}$ (keyword SPECHWHM=150.0). 


\section{Electrostatic Dipole Moments}

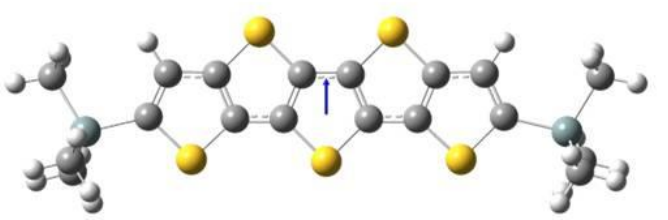

(2)

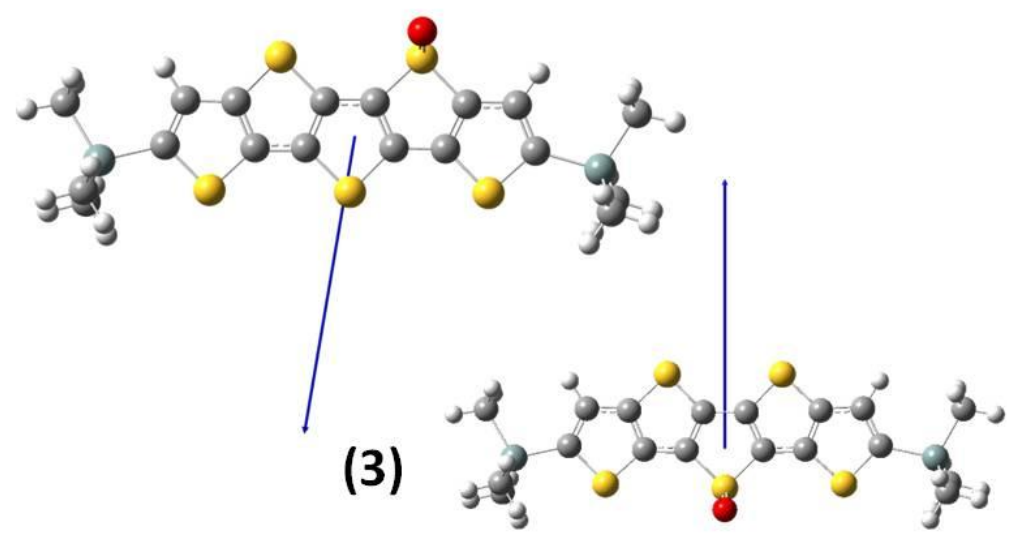

Figure S1. DFT/B3LYP/6-31G** electrostatic dipole 